\title{
She-austerity. Precariedad y desigualdad laboral de las mujeres en el sur de Europa
}

\author{
She-austerity. Women's precariousness and labor inequality \\ in Southern Europe
}

Mercedes Alcañiz / moscardo@uji.es
Universitat Jaume I. Castellón, España

Rosa Monteiro / monteiro.rosa14.@gmail.com

CES. Universidad de Coimbra, Portugal

\begin{abstract}
This article presents a comparative and longitudinal analysis of the situation of Spanish, Portuguese and Italian women since the beginning of the crisis. The study follows three specific objectives: expose the female labor market in the three states; analyze women's labor participation from the perspective of precariousness; and analyze the position of women and men in gender relations from the perspective of gender inequality. The research has been prepared by the technique of documentary analysis of secondary sources of official statistics. We conclude that the crisis has affected women from southern European countries in a similar manner because of their greater compliance with traditional gender roles, but at the same time, some differences between them are observed as a result of the different economic structures, labor legislation and social protection regimes.
\end{abstract}

Key words: crisis, women, South Europe, gender, precariousness.

Resumen: El artículo presenta un análisis comparativo y longitudinal de la situación de las mujeres en España, Portugal e Italia, desde el inicio de la crisis. Los objetivos específicos son: exponer el mercado laboral femenino en los tres países, examinar la presencia laboral de las mujeres desde la perspectiva de la precariedad y analizar la posición de mujeres y hombres en las relaciones de género desde la perspectiva de la desigualdad de género. La investigación se llevó a cabo mediante la técnica de análisis documental de fuentes secundarias de estadísticas oficiales. Se concluye que la crisis ha afectado a las mujeres de los países europeos del sur de manera similar por su mayor continuidad en el desempeño del rol de género tradicional, pero, a la vez, se observan algunas diferencias entre ellos como consecuencia de las diferentes estructuras económicas, legislaciones laborales y protección social.

Palabras clave: crisis, mujeres, Europa del sur, género, precariedad. 


\section{Introducción}

La crisis económico-financiera iniciada en 2007 en Estados Unidos y extendida posteriormente a la Unión Europea y al resto del mundo, también denominada Gran Recesión (Gil-Calvo, 2009; Touraine, 2011; Stiglitz, 2010); ataque que inició en la década de $1980,{ }^{1}$ al producirse cambios trascendentales en el sistema capitalista mundial que condujeron a la implementación del denominado neoliberalismo, término asociado con los economistas de la Escuela de Chicago: Friedich Hayek y Milton Friedan, y puesto en la práctica por Ronald Reagan en Estados Unidos y Margaret Thatcher en el Reino Unido.

El neoliberalismo (Harvey, 2007; Navarro, 1998; Steger y Roy, 2011) respondía a la fórmula de "más mercado y menos Estado" defendida por el Consenso de Washington en $1989^{2}$ y caracterizado por un proceso de privatización de bienes públicos y por una desregulación laboral definida por la flexibilidad como estrategia para garantizar la eficiencia empresarial (Stiglitz, 2002; 2010; Alonso, 2000; Estefania, 2012; Todaro y Yáñez, 2004).

La Gran Recesión se identifica por un crecimiento y desregulación del capital financiero, por un incremento de las desigualdades debido a las políticas fiscales que benefician a quienes más tienen, así como por el incremento de las rentas de capital, no de las rentas de trabajo que se ven disminuidas por la caída de los salarios, declive de las clases medias, reducción del gasto público, especialmente el correspondiente a protección social y reformas laborales que benefician a la desregulación y a la flexibilización (Do Carmo, 2011; $1^{\circ}$ y $2^{\circ}$ Informe sobre la desigualdad en España, 2013; 2015).

En el contexto de la Unión Europea no todos los Estados se han visto afectados por la crisis de manera similar. Los denominados países mediterráneos (Gálvez-Muñoz et al., 2013) -España, Italia, Grecia y Portugal- han sido los más perjudicados por ella, llegando a tener que ser rescatados -en el caso de Grecia y Portugal-, imponiéndose medidas de austeridad severas por la Troika $^{3}$ que condujeron a una reducción del Estado de Bienestar y a la aplicación de principios neoliberales. En el caso español, el rescate se centró en el sector bancario pero se aplicaron de igual forma las medidas de austeridad.

1 Gálvez-Muñoz (2013) señala las diferencias entre la Gran Recesión y las anteriores crisis aludiendo a que en la actual se ha producido una contracción y una crisis de la demanda.

2 El término fue acuñado por el economista John Williamson para describir un conjunto de diez fórmulas relativamente específicas, que consideró constituía el paquete de reformas "estándar" para los países en desarrollo en situación de crisis.

3 La denominada Troika hace referencia al FMI, al Consejo de Europa y al Banco Europeo. 
Con la crisis se aprobó una serie de medidas en el mercado laboral conducentes hacia una mayor flexibilidad, una reducción de los salarios y un crecimiento brutal de las formas atípicas de empleo. ${ }^{4}$ Además, se introdujeron medidas fiscales como el incremento del IVA y la reducción del Estado de Bienestar con recortes en el gasto público, especialmente en las políticas de cuidado y de apoyo a las familias, transfiriendo para el sector privado servicios anteriormente asegurados por el sector público (Esping-Andersen y Palier, 2010; Casaca y Damião, 2011; Ferreira, 2013; Gálvez-Muñoz, Rodríguez y Addabbo, 2013; Frade e Coelho, 2015; Rodríguez, 2010; 2014); todo ello en un contexto de descenso del PIB anual para los tres países analizados.

Teniendo en cuenta el hecho común acaecido en los países del sur, respecto a la severidad del impacto sufrido por la crisis y la austeridad, dichas naciones presentan características específicas y particulares en términos de modelo de organización de la protección y del bienestar social que llevaron a confirmar la existencia de un modelo de Estado de Bienestar Mediterráneo caracterizado por un escaso gasto público, acentuado familismo en los cuidados y en la protección social, fuertes asimetrías en la división sexual del trabajo, influencia de la Iglesia católica y bajas tasas de participación femenina en el mercado laboral (Esping-Andersen, y Palier, 2010; Silva, 2002; Tobío, 2015).

En este contexto de crisis y austeridad, una de las consecuencias más llamativas de la flexibilización laboral ha sido la expansión de la precarización en los empleos (Bourdieu, 1999; Alonso, 2000; Giordano, 2009; Standing, 2013; Recio, 2007). El denominado trabajador fordista, caracterizado por un empleo seguro, a tiempo completo, con horario semanal estipulado, con seguridad social y en un puesto de trabajo de por vida, ha dejado paso a un empleo precario y "desestandarizado" (Prieto et al., 2008) caracterizado por la inseguridad, un menor salario y una escasa protección social (Standing, 2013). La precarización es, pues, consecuencia de la flexibilización laboral y del cambio en las relaciones laborales (Leite, 2013).

Standing (2013) incluye en el "precariado" a los empleos temporales, a los empleos con jornada a tiempo parcial, a los denominados trabajadores/ as de los call center, a los becarios/as, a los contratistas dependientes o independientes, en relación con el autoempleo y al reemplazo de contratos de trabajo por contratos civiles o comerciales que distinguen actualmente a la externalización y subcontratación de actividades.

4 Ley 3/2012 del 6 de julio, de medidas urgentes para la Reforma Laboral (España). Ley 92/2012 Reforma Fornero y en 2014 la Ley de Bases de Reforma del Mercado de Trabajo (Jobs Act) (Italia). Ley 53/2011, Ley 23/2012, Ley 35/2014 del 20 de junio y Ley General de Trabajo para la Función Pública. 
Todos estos trabajos se caracterizan por la desestructuración de la existencia, así como por una inseguridad generalizada e institucionalizada que hace de la mera supervivencia el incentivo central y, por lo tanto, una herramienta disciplinaria en la sociedad actual (Bourdieu, 1999; Alonso y Fernández, 2013). En resumen, la precariedad se caracteriza por tres “i”: inestabilidad, inseguridad e insuficiencia (Todaro y Yáñez, 2004).

Junto con las características aludidas por los y las autoras señalados sobre la precariedad y la flexibilidad laboral como consecuencia de la crisis, se añade, para el caso concreto de las mujeres, las relacionadas con los roles de género. Roles que refuerzan el proceso de precariedad femenina respecto al desempeño del rol de cuidado y que determina, en la mayoría de los casos, el cómo, el dónde y el cuándo del desempeño de la actividad laboral (Cano, 2000; Del Boca y Sarraceno, 2005; De Luigi y Martelli, 2009; Casaca y Damiao 2011; Scott, Crompton y Lyonette, 2010; Ferreira, 2013; Ferreira y Monteiro, 2013; Castaño, 2015).

Dicho desempeño de las tareas de cuidados va unido a la tradicional división sexual del trabajo establecida por el patriarcado (Lerner, 1990; Walby, 1990; Connell, 1990) y que todavía define a los países del sur de Europa. Esta continuidad en el cumplimiento de las tareas domésticas y de cuidado contribuye, junto con otras cuestiones como la segregación laboral, a la desigualdad de las mujeres en el mercado laboral.

En este contexto de crisis económica, de austeridad y de reducción del Estado de Bienestar, nos preguntamos si, pese a la incorporación progresiva de las mujeres al empleo remunerado, dicho acceso se ha producido en condiciones más precarias para ellas que para los hombres, y si el impacto generado por la crisis ha sido similar para las mujeres de España, Italia y Portugal.

El objetivo general del presente artículo consiste en realizar un análisis comparativo y longitudinal de la situación de las mujeres españolas, portuguesas e italianas desde el inicio de la crisis. Este objetivo incluye, a su vez, tres específicos: exponer la situación laboral de las mujeres en España, Italia y Portugal, aludiendo al empleo y al desempleo; examinar la presencia laboral de las mujeres desde la perspectiva de la precariedad; y, finalmente, analizar la posición de mujeres y hombres en las relaciones de género desde la perspectiva de la desigualdad de género.

La hipótesis planteada apunta a que la crisis ha afectado, de manera similar, a las mujeres de los países europeos del sur por su mayor continuidad en el desempeño del rol de género tradicional manifestado en realizar las tareas de cuidado, pero, a la vez, se observan algunas diferencias entre ellos como consecuencia de las distintas estructuras económicas, legislaciones laborales y protección social. 


\section{Metodología}

La presente investigación se llevó a cabo mediante la técnica de análisis documental de fuentes secundarias estadísticas oficiales. Dado que el objetivo es realizar una comparación entre tres países, se optó por utilizar datos europeos, si bien en alguna ocasión, apuntada en su momento en el texto, se ha recurrido a fuentes estatales como el Instituto Nacional de Estadística (INE), el Instituto Italiano de Estadística (ISTAT) o el Instituto Estadístico Portugués (INE).

La fuente más consultada ha sido la Labor Force Survey (LFS) incluida en Eurostat, Oficina Europea de Estadística, encargada de producir y armonizar los datos procedentes de los países de la Unión Europea. La información de Eurostat nos ha permitido incluir datos seguros y fiables referentes a España, Italia y Portugal desde una perspectiva longitudinal diferenciada por sexos.

En la clasificación por sectores se ha ocupado la Clasificación Nacional de Actividades Económicas (CNAE_2009) de un dígito5 y para la clasificación de las ocupaciones hemos seguido las indicaciones de la CIUO-08 de la Unión Europea. ${ }^{6}$ El marco utilizado para construir la CIUO-08 se basa en dos conceptos principales: el de tipo de trabajo realizado o empleo y el de competencias. $^{7}$

La CIUO-88 incluye cuatro niveles de agregación: la más desagregada incluye 436 categorías de ocupaciones (cuatro dígitos); la categoría a tres

5 Agricultura, ganadería, silvicultura y pesca; Industrias extractivas; Industria manufacturera; Suministro de energía eléctrica, gas, vapor y aire acondicionado; Suministro de agua, actividades de saneamiento, gestión de residuos y descontaminación; Construcción; Comercio al por mayor y al por menor, reparación de vehículos de motor y motocicletas; Transporte y almacenamiento; Hostelería; Información y comunicaciones; Actividades financieras y de seguros; Actividades inmobiliarias; Actividades profesionales, científicas y técnicas; Actividades administrativas y servicios auxiliares; Administración pública y defensa, seguridad social obligatoria; Educación; Actividades sanitarias y de servicios sociales; Actividades artísticas, recreativas y de entretenimiento; Otros servicios; Actividades de los hogares como empleadores de personal doméstico, actividades de los hogares como productores de bienes y servicios para uso propio; Actividades de organizaciones y organismos extraterritoriales.

6 Los antecedentes de la CIUO (Clasificación Internacional Uniforme de Ocupaciones) se remontan a 1958 (OIT). Se han hecho adaptaciones posteriores.

7 Para mayor información sobre este tema puede consultarse Introducción a la CNO-11 (2012) en www.ine.es 
dígitos incluye 130 categorías, la de dos dígitos, 43 y la de un dígito, $10 .{ }^{8}$ En el presente artículo se ha usado la clasificación a un dígito y la de dos dígitos para la de ocupaciones masculinizadas, feminizadas y mixtas al proporcionar mayor concreción y facilitando la clasificación de forma más rigurosa. ${ }^{9}$

Para el análisis de los usos del tiempo se ha recurrido a la Harmonised European Time Use Survey (Hetus Project) (2007). La base de datos HETUS hace una comparación de las encuestas de usos del tiempo de 15 países de la Unión Europea basadas en las actividades realizadas en las 24 horas diarias. Esta clasificación permite la comparación entre los países, en este caso Italia y España, al ser idénticas las actividades incluidas. No se ha podido contar con información sobre los usos del tiempo en Portugal, debido a que la última encuesta fue la del año 1999.

De las fuentes consultadas se han seleccionado los datos estadísticos relacionados con los objetivos de la investigación, construyendo un listado de indicadore ${ }^{10}$ que facilitará la comparación entre los tres países y la medición del concepto señalado:

a. Indicadores de Estructura laboral femenina: Acortando distancias en el empleo y el desempleo de las mujeres del sur de Europa; la segregación laboral femenina; sectores y ocupaciones.

b. Indicadores de precariedad laboral: Ser precaria en el sur de Europa; temporalidad; jornadas a tiempo parcial; la brecha salarial como manifestación de la precariedad; el autoempleo.

8 Directores y gerentes; Profesionales científicos e Intelectuales; Técnicos y profesionales de nivel medio; Personal de apoyo administrativo; Trabajadores de servicios y vendedores de comercios y mercados; Agricultores y trabajadores cualificados; Agropecuarios, forestales y pesqueros; Oficiales, operarios y artesanos de artes mecánicas y de otros oficios; Operadores de instalaciones y máquinas y ensambladores; Ocupaciones elementales; y por último, Fuerzas Armadas.

9 Las ocupaciones masculinas son aquellas en las que los hombres ocupan $60 \%$ o más de los puestos de trabajo: mecánicos y trabajadores del metal, conductores, trabajadores de la construcción, ingenieros e informáticos, trabajadores de la industria, managers y operarios. Las ocupaciones feminizadas, con $60 \%$ o más de mujeres, son: profesionales de la salud, cuello blanco, personal dedicado al cuidado, sector educativo, trabajadoras de la limpieza y mantenimiento, personal de ventas, empleados de servicio al cliente. Las ocupaciones mixtas en las que participan mujeres y hombres de forma similar son: las relacionadas con los sectores de la alimentación, el mueble y el textil, la administración pública, la abogacía, y los profesionales científicos, las finanzas y el comercio (CUO-08 a dos dígitos).

10 Carmona (1977) define a los indicadores sociales como "la medida estadística de un concepto o de una dimensión de un concepto o de una parte de aquélla, basado en un análisis teórico previo e integrado en un sistema coherente de medidas semejantes que sirva para describir el estado de la sociedad". 
c. Indicadores de desigualdad en el rol de cuidados: la distribución del tiempo diario como eje de desigualdad; excedencias y permisos por cuidado de niños/niñas y dependientes; abandono del empleo por motivo de cuidado.

El ámbito espacial se centra en los países del sur de Europa, España, Italia y Portugal. ${ }^{11}$ El ámbito temporal contemplado se sitúa en los diez últimos años: 2004-2014. Esta decisión se debe al propósito de incluir datos previos a la crisis, durante la crisis y actuales.

\section{Estructura laboral femenina}

\section{Acortando distancias. Empleo y desempleo de las mujeres del sur de Europa}

Los estudios e investigaciones realizados en Europa desde el inicio de la crisis apuntan a que, en una primera fase (Torns, 2011; Ferreira, 2013; Bettio, Corsi et al., 2013; Karamessini y Rubery, 2013; Pavolini, 2014; Castaño, 2015), la crisis afectó más a los hombres (segundo trimestre de 2008) y que, posteriormente, cuando se empezaron a implementar las medidas de austeridad impuestas por la Troika, las mujeres fueron más afectadas debido a los recortes en el sector público.

La tasa de empleo femenina ${ }^{12}$ se ha mantenido desde el inicio de la crisis acortándose la distancia entre la ocupación masculina y la femenina (Alcañiz y Guerreiro, 2009; Ferreira, 2010; Leon, 2013; Alcañiz, 2015), siendo actualmente de 8,5 puntos porcentuales en España, 17,9 en Italia y 6,2 en Portugal. Bettio y Verashchagina (2014) consideran que el levelling down se debe más al empeoramiento de la participación masculina que a la mejora de los resultados laborales de las mujeres.

Ellas, más sensibles a los ciclos económicos que los hombres, se incorporan al mercado laboral por motivos de necesidad económica de la familia, como es el caso de encontrarse la pareja en paro (Gálvez et al., 2013). Hoy en día son más las mujeres casadas quienes se han incorporado a un empleo que las jóvenes, debido a las dificultades que tiene la juventud de encontrar un empleo antes de los 24 años. En este aspecto, se ha producido un cambio respecto a crisis anteriores, cuando las mujeres se iban a casa para dejar los trabajos a los hombres (Gálvez-Muñoz et al., 2013).

11 No se incluye a Grecia pese a considerarse un país del sur por sus diferencias históricas y culturales respecto a los otros tres países.

12 Referida a mujeres con edades comprendidas entre los 16 y los 64 años. 
La Gráfica $1^{13}$ muestra la evolución en la tasa de ocupación femenina en los tres países. Se observa que el empleo masculino mantiene una homogeneidad entre estos tres, mientras que el perfil del empleo femenino se diferencia, siendo Portugal el país con mayor presencia femenina en el mercado laboral..$^{14}$

La crisis ha tenido consecuencias desastrosas respecto al desempleo, existiendo diferencias notables en los tres países del sur de Europa (Ingellis y Calvo, 2015; Ferreira, 2013). La más llamativa es el triple incremento en la tasa de desempleo de los hombres españoles y el doble en las mujeres españolas. Mujeres y hombres italianos y portugueses han aumentado su tasa de desempleo pero no en la misma proporción que en España (véase Gráfica 2). ${ }^{15}$

El desempleo se agrava para aquellas personas que llevan más de 12 meses en esta situación, son los denominados desempleados de larga duración (DLD). En Europa, en su conjunto, los DLD tienen un peso muy relevante en el total del desempleo. De hecho, casi la mitad (entre el 40 y el $45 \%$ ) del desempleo total corresponde a DLD (De la Rica y Brindusa, 2014). Respecto a los tres países del sur de Europa, la evolución desde el inicio de la crisis hasta 2015 es la que se puede observar en la Tabla 1.

Este incremento en los DLD se debe a la recesión económica y a causas estructurales económicas (De la Rica y Brindusa, 2014): por parte de la oferta de trabajo, el desajuste entre las habilidades o competencias demandadas y las ofrecidas; por parte de la demanda, la reducción de ésta debido a un interés por ahorrar en los salarios; por parte de las políticas laborales y fiscales del Estado, por las altas contribuciones a la Seguridad Social, alta protección al empleo y subsidios de desempleo generosos y duraderos que desaniman, en el actual contexto de crisis, la búsqueda de trabajo.

\section{Continuidad en la segregación. Sectores y ocupaciones}

Desde la configuración de la sociedad laboral, los agentes sociales participantes establecieron una diferenciación -segregación- entre los puestos de trabajo asignados a mujeres y los asignados a los hombres (Scott, 1995), instaurándose una división según el género persistente hasta nuestros días. La segregación es la materialización en el mercado laboral de la división sexual

13 Todas las gráficas y las tablas se encuentran en el Anexo, al final del presente artículo (Nota de los editores).

14 Superior a la media Europea en 2014.

15 La crisis afectó inicialmente a sectores muy masculinizados, como la construcción y la industria. 
del trabajo, que establece una desigualdad en salarios, jerarquía y condiciones laborales (Ibáñez, 2008). Sus causas son, por una parte, culturales, en concreto por el desempeño de los roles de género; y, por otra, a una configuración del mercado laboral, que establece una clasificación de los puestos de trabajo con "asignación de género", perjudicando la inclusión de las mujeres en ellos.

La segregación genera desigualdades en cuatro aspectos (Burchell et al., 2014): 1) reduce las elecciones de empleo y refuerza los estereotipos de género; 2) produce una segregación vertical (tendencia de los hombres a tomar trabajos mejores) y una horizontal (mujeres y hombres escogen diferentes tipos de trabajos); 3) puede ser el resultado de la elección de empleos que permitan conciliar la vida laboral y la familiar; 4) facilita la subvaloración de los empleos ocupados mayoritariamente por mujeres.

Además, un mercado laboral segregado restringe las oportunidades de las mujeres de cambiar la división sexual del trabajo en el hogar, debido a que ellas tienen menos acceso a los empleos pagados cualificados que los hombres.

Los análisis realizados para el conjunto de países de la Unión Europea (Smith et al., 2013) aluden a la alta segregación laboral por género, a causa de la permanencia de los estereotipos de género sobre los empleos y a la elección por parte de las mujeres de empleos en sectores con horarios asequibles que permitan conciliar la vida laboral con la familiar, reforzando así la segregación. Las gráficas 3 y 4 muestran los cambios en la participación laboral femenina por sectores.

El comercio es el sector donde participan más mujeres en España e Italia y el segundo en importancia en Portugal. La educación, la sanidad y los servicios sociales son también sectores feminizados; en tanto, las industrias manufactureras tienen presencia en los tres países pero con diferentes posiciones: en primera en Portugal, en segunda en Italia y en cuarta en España (véase Gráfica 4).

Los cambios observados en la participación laboral femenina por sectores en estos años de crisis apuntan a una desaparición del empleo manufacturero del ranking de los cuatro sectores en España, manteniéndose en Italia y Portugal, pero disminuyendo su proporción. El comercio, la sanidad y la educación son los tres sectores prioritarios en el empleo femenino, y en España, la hostelería se ubica entre los cuatro primeros.

Como conclusión sobre dónde se ocupan las mujeres, los datos reflejan un incremento notable en los años estudiados y para los tres países en: la administración pública, la educación y la sanidad. Hay un ligero incremento en el sector del transporte y almacenaje y en las actividades profesionales, y una continuidad en el resto de los sectores. 
Para conocer el índice de segregación de las diferentes ocupaciones, se elaboró una clasificación ${ }^{16}$ basada en el análisis de la ocupación por mujeres y hombres, considerando una ocupación como segregada si en ella hay más de $60 \%$ de hombres o de mujeres. Los resultados dan lugar a ocupaciones masculinizadas, feminizadas ${ }^{17}$ y mixtas. La Tabla 2 muestra la distribución de la población ocupada por sexos y por tipo de clasificación.

España y Portugal tienen una segregación más grande que Italia, debido al mayor número de mujeres laborando en sectores feminizados y menos en sectores mixtos o masculinizados; mientras, en Italia la ocupación femenina tiene una proporción más alta en los trabajos mixtos. En términos generales, para los tres países, el acceso de las mujeres a las ocupaciones masculinas es menor que el acceso de los hombres a los trabajos feminizados.

\section{Ser precaria en el sur de Europa}

\section{Una figura laboral feminizada: La jornada a tiempo parcial}

El trabajo a tiempo parcial evidencia la reorganización laboral, la flexibilización y la precariedad para las mujeres, manifestando la segmentación ${ }^{18} \mathrm{de}$ género que se produce en el mercado laboral en este contexto de crisis (Torns y Carrasquer, 2007; Monteiro, 2010; Ortiz, 2014; Pace, 2014). Desde 2008 hasta 2015, la tasa de empleo a jornada parcial se ha incrementado en España e Italia pero no en Portugal, país donde este tipo de jornada tiene menos presencia debido a los bajos salarios. ${ }^{19}$

El trabajo a tiempo parcial manifiesta la segmentación desigual existente en la actualidad en el mercado laboral por motivo de género. Su crecimiento

16 Expuesta en el apartado de Metodología.

17 Las ocupaciones feminizadas fueron denominadas por Louise Kappe Howe (1977) como "pink-collar" o "cuello rosa". Se popularizaron en los años noventa con el incremento masivo de las mujeres en el mercado laboral de enfermeras, secretarias, maestras en guarderías y educación primaria.

18 La Teoría de la segmentación del mercado laboral fue planteada por Piore y Sabel (1990), quienes dividen a éste en: 1) mercado laboral primario con trabajadores cualificados, buenos salarios, estabilidad laboral y posibilidades de promoción; y 2) mercado laboral secundario, caracterizado por la temporalidad, la inestabilidad, la rotación en el empleo, los salarios bajos y las escasas posibilidades de promoción. Los y las trabajadoras precarias se identificarían con este último segmento.

19 En Portugal el salario mínimo es de 589 euros y en España, de 655,20 euros. Desde 2009 hasta 2016, en España el salario mínimo se ha incrementado 31 euros. 
alude a la posibilidad de permitir la conciliación de la vida laboral y familiar, y a la creación de puestos de trabajo con este perfil flexible. En ambos casos afecta más a las mujeres, debido al desempeño del rol de cuidado y a la consideración de esta jornada, peor pagada, con nulas posibilidades de promoción y con una menor jubilación futura, más relacionada con grupos no considerados con el modelo de breadwinner, reflejando sin ninguna duda la pervivencia del patriarcado en la sociedad (Casaca, 2012; Alcañiz, 2015).

Si cruzamos la clasificación por sectores masculinizados, feminizados o mixtos con el tipo de jornada laboral, obtenemos los resultados que se pueden observar en la Tabla 3.

Las mujeres ocupan jornadas a tiempo parcial mayoritariamente en sectores feminizados. Se produce, pues, una doble desigualdad, en la segregación y en la segmentación, ya que junto con la menor valoración, y consiguiente menor retribución de los empleos en sectores feminizados, se suma el hecho de que sean a tiempo parcial, con lo cual la precariedad y la desigualdad se agudizan en el caso de las mujeres trabajadoras en sectores feminizados a tiempo parcial, en España y en Portugal.

\section{La inestabilidad permanente: la temporalidad laboral}

El contrato temporal cumple con las exigencias de flexibilidad empresarial según las necesidades productivas, dando lugar a otra segmentación laboral donde las mujeres son también perdedoras (Juan, 2015). El trabajo temporal ha degradado las condiciones laborales y ha servido, junto con el paro masivo, para disciplinar a la fuerza de trabajo en sus demandas salariales y en la defensa de sus derechos laborales individuales y colectivos (Alonso y Fernández, 2013; Lorente, 2014).

Se observan diferencias entre los países del sur de Europa debido a las diferentes regulaciones y estructura de sus mercados económicos y laborales. ${ }^{20}$ España, si bien ha descendido su proporción en los últimos años, sigue siendo el país con mayor tasa de temporalidad. En opinión de Otaegui (2014), el descenso de la temporalidad se debe a que la crisis se ha llevado por delante a los empleos temporales -los primeros afectados-, por lo que, con seguridad, los y las anteriores trabajadoras temporales habrán ido a engrosar las listas del desempleo, máxima expresión de la precariedad (Larrañaga, 2014).

En Portugal se verifica que con la crisis hubo un aumento de la situación de temporalidad para los hombres y una caída para las mujeres; esto refleja 20 Es importante no olvidar la relación entre temporalidad y sectores económicos. Por ejemplo el sector turístico y la construcción. 
el fenómeno que Virginia Ferreira (2013) denomina "feminización" de las condiciones laborales de los hombres, ahora sujetos a formas de precariedad anteriormente mayoritarias para las mujeres. Este hecho ha acaecido también en Italia, donde la tasa de temporalidad femenina, aunque superior a la masculina, ha permanecido constante, mientras que la de los hombres se ha incrementado.

Ingellis y Calvo (2015) afirman que en Italia el mercado laboral es más rígido y por ello la temporalidad es menor, produciéndose a la vez una dualidad entre los y las trabajadoras en relación con la protección social, ya que en Italia ésta es menor que en España.

\section{Crea tu puesto de trabajo: El autoempleo}

En la Unión Europea y según datos recientes (Hatfield, 2015), el 14\% de los y las trabajadoras europeas trabajan en la modalidad de autoempleo o self-employed. Los sectores donde ejercen su actividad varían, van desde la agricultura, los profesionales free-lance y el personal de limpieza. El país europeo con más autoempleo es Grecia, pero Italia y España también presentan proporciones elevadas.

Se considera una figura laboral precaria porque es una vía rápida para introducirse en el mercado laboral, pero las condiciones de trabajo son peores al no tener cobertura de desempleo ni protección social, menor salario (hasta un $40 \%$ menos) e inestabilidad. Hatfield (2015) alude a que su satisfacción es mayor que en el resto de asalariados al ser su propio jefe o jefa y organizar la jornada laboral por sí mismos/as; sin embargo, la situación de inseguridad e inestabilidad les lleva, en su mayoría, a buscar un empleo que cubra estas demandas.

Hay más autoempleo masculino que femenino, pero este último se está incrementando con la crisis y de manera especial en empleos menos cualificados donde las condiciones laborales son malas pero permiten la conciliación. En opinión de Hakim (2005), se trata de una manifestación más de que las mujeres buscan un empleo que les permita desempeñar el rol de cuidado de forma satisfactoria.

Desde la Unión Europea y desde los gobiernos se están poniendo en marcha iniciativas para incentivar el autoempleo; como son todas las ayudas a emprendedores/as: mediante la facilitación de créditos a bajo interés para crear e iniciar empresas autónomas. Asimismo, el Fondo Social Europeo facilita subvenciones a fondo perdido para apoyar nuevas iniciativas. Las gráficas 5 y 6 muestran los cambios en la precariedad femenina entre los años 2008 y $2015 .{ }^{21}$

21 En ambos casos incluyen datos del tercer trimestre. 


\section{Objetivo pendiente: disminuir la brecha salarial}

Consecuencia de la segmentación y de la segregación, se produce otra desigualdad entre mujeres y hombres: la referida a los salarios. Si bien el objetivo de la igualdad laboral ha estado presente en la Unión Europea desde su creación, ${ }^{22}$ lo cierto es que dicho objetivo sigue siendo uno de los talones de Aquiles respecto a la igualdad que se produce en la Unión Europea, ya que ningún país ha conseguido alcanzarlo. Ello ha llevado a que la Comisión Europea establezca el Día Europeo de la Igualdad Salarial, evento organizado para sensibilizar al público acerca de este hecho.

Este día varía dependiendo de la brecha salarial (gap) entre mujeres y hombres, siendo el 5 de marzo de 2011 la primera ocasión en que se celebró. ${ }^{23}$ Según el Informe de la Comisión Europea (2014), la brecha salarial europea era en 2011 del 16\%, descendiendo un poco respecto a 2008, que fue del $17,3 \%$. En cuanto a España, fue ligeramente superior, del 17,8\%, mientras que en Italia fue sorprendentemente inferior, situándose en 6,7\%. Ambos países han incrementado su brecha salarial en los últimos años: así, en 2013, según el último dato proporcionado por Eurostat (2015), la brecha ha aumentado en España al 19,3\%, Portugal al 13\% y en Italia al 7,3\%.

La desigualdad entre mujeres y hombres respecto a la brecha salarial es superior en España, por lo cual se evidencia la mayor precariedad laboral femenina relacionada, a su vez, con los otros factores de precariedad aludidos con anterioridad.

Las causas de que se produzca una diferenciación de salarios entre mujeres y hombres se debe fundamentalmente a las siguientes causas (Informe de la Comisión Europea, 2014): en primer lugar al hecho de que mujeres y hombres están en el mercado laboral en ocupaciones y sectores diferentes; los que ocupan las mujeres son, por lo general, peor pagados.

En segundo lugar, las mujeres, en muchas ocasiones, tienen empleos de jornada a tiempo parcial peor remunerados; en tercer lugar se sitúa el aspecto cultural en lo referente al desempeño de roles, en el cual las mujeres son mayormente las responsables de las tareas domésticas y de cuidado, hecho que limita su mayor implicación con el puesto de trabajo y su posible promoción; en cuarto lugar, el hecho de que se infravalore los puestos de trabajo ocupados por mujeres da lugar a que en el sistema salarial se asignen retribuciones menores; y en quinto y último lugar, sigue permaneciendo

22 El Tratado de Roma de 1957 y las directivas aprobadas que aluden a la igual retribución para un trabajo de igual valor (Directiva 2006/54/CE).

23 En este año 2016 se celebró el 22 de febrero. 
todavía el estereotipo de que el sueldo de la mujer es un segundo sueldo, no el principal; el imaginario colectivo continúa asignando al hombre el papel de proveedor familiar, tal y como se institucionalizó en un principio.

\section{La persistente desigualdad: el desempeño de los roles de género}

Como se ha señalado con anterioridad, la crisis ha afectado de diferente manera a mujeres y a hombres: por una parte, ha llevado a ellas a incorporarse al mercado laboral, disminuyendo el gap en la presencia de mujeres y hombres en el mercado de trabajo; y por otra, ha incrementado su situación de precariedad, debido a la flexibilización y segregación laboral y al desempeño del rol de cuidado (Carrasco et al., 2011).

Si a ello sumamos los recortes que los Estados han realizado en su gasto social, la situación se complica para las mujeres, produciéndose, en palabras de Gálvez et al. (2013), un austericidio femenino que afecta de forma especial a las mujeres con menos recursos.

\section{Los usos del tiempo como ejes de desigualdad}

El estudio de los usos del tiempo como medición en el análisis sociológico sobre el género se ha convertido en una herramienta básica que visibiliza las desigualdades entre mujeres y hombres (De la Fuente, 2007; Durán y Rogero, 2009; Martin Criado y Prieto, 2015; García Sainz, 2015). Si bien el tiempo es el mismo para todos y todas, su uso difiere en función de variables sociales, entre las cuales el género es una de las más importantes; de ahí el interés en medir la distribución temporal de las actividades realizadas a lo largo del día, así como en su interpretación aplicando la perspectiva del género.

Los datos obtenidos mediante las encuestas llevadas a cabo también han sido objeto de críticas (Carrasco et al., 2011), debido a la consideración de que los trabajos de cuidados son mucho más complejos de medir que el resto de tareas realizadas a lo largo del día, pues no se puede hacer únicamente con una medición en horas y minutos (véase Tabla 5).

Las españolas dedican más tiempo al empleo que las italianas y, en consonancia, menos a las tareas de cuidado. Respecto a los hombres, la distribución es similar, y, para ambos sexos, el tiempo libre es superior en España que en Italia. 
La asimétrica dedicación de mujeres y hombres a las tareas domésticas y de cuidado conduce a la denominada "brecha de cuidado" y manifiesta la continuidad en el desempeño de las tareas domésticas y de cuidado por parte de las mujeres ${ }^{24}$ (Orloff, 2009; Tobío, 2005; Sarraceno, 2004; Pandolfini, 2014; Alcañiz, 2015).

\section{Excedencias, permisos y abandonos por motivos de cuidado}

Como se ha apuntado antes, el interés de la Unión Europea ${ }^{25}$ por incorporar a las mujeres al mercado laboral remunerado favoreció la aprobación de diversas normativas agrupadas bajo el concepto de conciliación de la vida laboral y personal, con el objetivo de que las personas que tuvieran criaturas o dependientes a su cargo dispusieran de una serie de medidas relacionadas con el abandono temporal del trabajo, la flexibilización o la reducción de la jornada laboral, sin que ello les supusiera apartarse definitivamente del empleo. Entre estas medidas destacan la excedencia por cuidado, la reducción de jornada, el permiso de lactancia y la flexibilización laboral.

En relación con las interrupciones en la vida laboral o las reducciones de jornada, los datos muestran que fundamentalmente "es cosa de mujeres"; es decir, a pesar de que las leyes de conciliación aprobadas en Italia, en España y en Portugal se dirigían a los dos géneros, eran "neutras". La decisión de alterar la trayectoria laboral sigue siendo algo femenino (Alcañiz, 2012). Es importante señalar que Portugal es el país del sur de Europa donde la presencia de hijos/as menores de ocho años determina el abandono del empleo o la reducción de jornada, por los bajos salarios (véase la Tabla 6).

La continuidad en el desempeño del rol doméstico y de cuidados se confirma con estos datos, y se reafirma cuando se corrobora que la reducción de la jornada laboral de las mujeres aumenta según el número de hijos/as menores de seis años que tengan. Así, en 2013,34,1\% de las mujeres italianas

24 En este desempeño se producen diferencias notables entre las mujeres: según vivan en un estado con mayor provisión de servicios de cuidado, según clase social o según se comparta una ideología más igualitaria entre los géneros.

25 La Cumbre de Luxemburgo de 1997 aprobó la Estrategia Europea de Empleo. En ella se animaba a los Estados a implementar políticas que introdujeran la jornada a tiempo parcial, permisos parentales y servicios de cuidados a criaturas y dependientes. En España se aprobó la Ley 39/1999 para promover la conciliación de la vida familiar y laboral de las personas trabajadoras. En Italia, en el año 2000, se aprobó la Ley para el apoyo de la maternidad y la paternidad, por el derecho al cuidado y a la formación y para la coordinación de los tiempos de las ciudades (Ley Turco) mucho más completa que la española. 
con un hijo/a trabaja a tiempo parcial, mientras que quienes tienen tres hijos/as o más representan $42,6 \%$.

Esta disimilitud es todavía más marcada en la Unión Europea, donde la diferencia porcentual entre las mujeres que tienen un hijo/a y las que tienen tres o más respecto al empleo a tiempo parcial es de casi 14 puntos. Esta variación no sucede en España, donde los porcentajes de tiempo parcial no varían según el número de hijos/as (29,5\% en 2004 y 30,1\% en 2013) (Eurostat, 2015).

\section{El cuidado como "inactividad" laboral}

La población inactiva en una sociedad incluye a las personas que no están en el mercado laboral remunerado, ya sea porque están estudiando, porque ya han estado empleadas y ahora cobran una pensión, o porque son dependientes física o psicológicamente. También se incluye a las mujeres dedicadas exclusivamente a las tareas domésticas y de cuidados, aspecto muy discutido y reivindicado por las feministas como "trabajo", así como su inclusión en el PIB del país, el cual con toda probabilidad se incrementaría debido al importante número de mujeres dedicadas a las tareas del hogar en los países del sur de Europa.

En los tres países analizados ha disminuido la proporción de mujeres inactivas entre 2008 y 2015: en España el descenso ha sido de cinco puntos porcentuales, de dos en Italia y de 1,3 en Portugal. Es decir, la figura tradicional de mujer dedicada al cuidado de la familia como tarea fundamental ${ }^{26}$ se ve cada vez menos, dejando paso a otro modelo de mujer incorporada al mercado laboral, pero -y esto es lo más importante (y más desigual)- dedicada también a las tareas domésticas y de cuidado.

No obstante, este último sigue siendo el principal factor explicativo del porqué muchas mujeres, incluso deseando incorporarse al mercado laboral, no buscan empleo y priorizan dicha tarea a la de desempeñar un trabajo remunerado fuera del hogar (véase la Gráfica 7).

\section{Conclusiones}

La crisis y las políticas de austeridad han afectado de forma muy significativa y desproporcionada a las mujeres del sur de Europa, agravando los regímenes de género vigentes. Respecto al desempleo, se ha agravado en estos tres países, 26 Modelo defendido por la Iglesia católica, por la Dictadura Franquista en España hasta 1978 y por el Estado Novo portugués hasta 1976. 
pero con diferencias notables entre ellos. La más llamativa es el triple incremento en la tasa de desempleo de los hombres españoles y el doble en las mujeres españolas. Mujeres y hombres italianos y portugueses han aumentado su tasa de desempleo pero no en la misma proporción que en España.

El autoempleo es más masculino que femenino; sin embargo, este último se está incrementando con la crisis y de manera especial en empleos menos cualificados donde las condiciones laborales son malas pero permiten la conciliación.

Los datos indican que España y Portugal tienen una segregación mayor que Italia, debido al mayor número de mujeres trabajando en sectores feminizados y menos en sectores mixtos o masculinizados, mientras que en Italia la ocupación femenina tiene una proporción más alta en las ocupaciones mixtas. En términos generales, para los tres países, el acceso de las mujeres a los trabajos masculinos es menor que el acceso de los hombres a los trabajos feminizados.

Se produce una doble desigualdad, de segregación y de segmentación, ya que junto con la menor valoración, y consiguiente menor retribución de los empleos en sectores feminizados, se aúna el hecho de que sean a tiempo parcial, con lo cual la precariedad y la desigualdad se agudizan en el caso de las mujeres trabajadoras en sectores feminizados a tiempo parcial, en España y Portugal. Entre 2008 y 2015, la tasa de empleo a jornada parcial se ha incrementado en España e Italia, pero no en Portugal, donde este tipo de jornada tiene menos presencia por los bajos salarios.

Se observan diferencias entre los países del sur de Europa en la evolución del trabajo temporal, debido a las distintas regulaciones y estructura de sus mercados económicos y laborales. España, si bien ha descendido su proporción en los últimos años, sigue siendo el país con mayor tasa de temporalidad. En Portugal se verifica que con la crisis aumentó la situación de temporalidad para los hombres y hubo una caída para las mujeres, lo cual refleja el fenómeno que Virginia Ferreira (2013) denomina “feminización” de las condiciones laborales de los hombres, ahora sujetos a formas de precariedad anteriormente mayoritarias para las mujeres.

Este hecho también se ha registrado en Italia, donde la tasa de temporalidad femenina, aunque superior a la masculina, ha permanecido constante mientras que la de los hombres ha aumentado. Ingellis y Calvo (2015) afirman que en Italia el mercado laboral es más rígido y por ello la temporalidad es menor, produciéndose a la vez una dualidad entre los y las trabajadoras en relación con la protección social, pues en Italia ésta es menor que en España. 
Las brechas salariales se han incrementado en todos los países, más en España, por lo cual se evidencia la mayor precariedad laboral femenina relacionada, a su vez, con los otros factores de precariedad.

Con la crisis, la precariedad se agravó para las mujeres europeas del sur por tres aspectos (Bettio y Verashchagina, 2014): en primer lugar, el grado de segmentación y segregación de la estructura laboral que afecta a la ocupación femenina; en segundo, la mayor o menor persistencia de los roles tradicionales de género que llevan a las mujeres a elegir puestos de trabajo en función de la posibilidad de conciliar con su "otro rol"; y en tercer lugar, el retrenchment de los estados de bienestar, las ayudas ofrecidas por el Estado, no sólo en cuanto a medidas de conciliación de la vida laboral o familiar, sino en cuanto a prestación de servicios de cuidado que conduzcan a la consecución de una "desfamiliarización" ${ }^{27}$ siendo el Estado quien asuma los trabajos de este último (Moreno, 2007).

Las políticas generalizadas de austeridad han conducido a que vuelvan a ser las familias las que provean muchos de los servicios prestados por el Estado, siendo las mujeres las principales responsables de hacerlo.

\section{Referencias}

Alcañiz, Mercedes y María das Dores-Guerreiro (2009), “Tiempos, trabajos e identidades. Análisis comparativo entre las mujeres españolas y portuguesas”, en Asparkia, núm. 20, Castellón de la Plana.

Alcañiz, Mercedes (2012), "Conciliación de la vida laboral y familiar. ¿Cuestión de género o cuestión de mujeres?”, en Vélez, Graciela y Norma Baca [eds.], Género y desigualdades en Iberoamérica, Mnemosyne: Buenos Aires.

Alcañiz, Mercedes (2015), Crisis, precariedad y desigualdad de género en España y en Italia, Obets. Disponible en: http://hdl.handle.net/10045/48651 [23 de enero de 2016].

Alonso, Luis Enrique (2000), Trabajo y posmodernidad. El empleo débil, Madrid: Fundamentos.

Alonso, Luis Enrique y Carlos J. Fernández (2013), Los discursos del presente. Un análisis de los imaginarios sociales contemporáneos, Madrid: Siglo XXI.

Bettio, Francesca et al. (2013), The impact of the Economic Crisis on the Situation of Women and Men and on Gender Equality Policies. Disponible en: http://ec.europe.eu/justice/ gender-equality / files/130522 [10 de mayo de 2015].

Bettio, Francesca y Alina Verashchagina (2014), "Women and Men in the Great European Recession”, en Karamessini, María y Jill Rubery [eds.], Women and Austerity. The Economic Crisis and the Future for Gender Equality, London: Routledge.

27 El término "desfamiliarización” fue introducido por Gosta Esping-Andersen (2000), después de recibir críticas por parte de las feministas. Se define como el proceso mediante el cual los individuos han conseguido emanciparse de las dependencias familiares a través de la actuación de los Estados. 
Mercedes Alcañiz y Rosa Monteiro. She-austerity. Precariedad y desigualdad laboral de las mujeres en el sur de Europa

Bourdieu, Pierre (1999), Contrafuegos, Madrid: Akal.

Burchell, Brendan et al. (2014), A New Method to Understand Occupational Gender Segregation in European Labour Market, Luxemburgo: European Commission.

Cano, Ernest (2000), Precariedad laboral, flexibilidad y desregulación, Valencia: Germania.

Carmona, José Antonio (1977), Los indicadores sociales hoy, Madrid: CIS.

Carrasco, Cristina et al. [eds.] (2011), El trabajo de cuidados. Historia, teoría y politicas, Madrid: La Catarata.

Casaca, Sara F. y Damiao, Sónia (2011), “Gender (In)equality in the labour market and the Southern European Welfare States”, en Addis, Elisabetta et al., Gender and Well-being, Londres: Ashgate.

Casaca, Sara F. (2012), Mudanças laborais e relaçoes de género, Coimbra: Almedina.

Castaño, Cecilia [dir.] (2015), Las mujeres en la Gran Recesión, Madrid: Cátedra.

Castel, Robert (1997), La metamorfosis de la cuestión social: una crónica del salariado, Buenos Aires: Paidós.

CNO-11 (2012), Clasificación Nacional de Ocupaciones. Disponible en: www.ine.es/jaxi/ menu.do type $=$ pcaxis \&path $=/ \mathrm{t} 40 /$ cnol $1 \&$ file $=$ inebase $[30$ de noviembre de 2014] .

Connell, R.W. (1990), “The State, Gender and Sexual Politics: Theory and Appraisal”, en Theory and society, vol. 19, núm. 5, Davis: The University of California.

De la Fuente, Miguel [dir.] (2007), Usos del tiempo, estereotipos, valores y actitudes, Madrid: Instituto de la Mujer.

De Luigi, Nicola y Alessandro Martelli (2009), "Transizioni di genere fra tradizione, innovazione e precarietà, en Actas del Convegno Genere e precarietà, Trento: Commisione provinciale per le pari opportunitá tra uomo e donna.

Del Boca, Daniela y Chiara Sarraceno (2005), “Le donne in Italia tra familia e lavoro”, en Economia \& Lavoro, núm. 1, Roma: Carocci editore.

De la Rica, Sara y Anghel Brindusa (2014), "Los parados de larga duración en España en la crisis actual", en Documento de Trabajo, núm. 185, Madrid: Laboratorio Alternativas.

Do Carmo, Renato Miguel [coord.] (2011), Portugal uma sociedade de clases: polarização social e vulnerabilidade, Lisboa: Ediçoes 70, Le Monde Diplomatique.

Duby, Georges y Michelle Perrot (1995), Historia de las mujeres, IV Volumen Siglo XIX, Barcelona: Círculo de Lectores.

Durán, Ma Ángeles y Jesús Rogero (2009), La investigación sobre los usos del tiempo, Madrid: CIS.

Esping-Andersen, Gosta (2000), Fundamentos sociales de las economias post-industriales, Barcelona: Ariel.

Esping-Andersen, Gosta y Bruno Palier (2010), Los tres grandes retos del Estado de bienestar, Barcelona: Ariel.

Estefanía, Joaquin (2012), La economía del miedo, Barcelona: Círculo de Lectores.

Eurostat (2015), Eurostat Database. Disponible en http://ec.europa.eu/eurostat [12 de diciembre de 2015].

Ferreira, Virginia (2010), A igualdade de Mulheres e Homens no Trabalho e no emprego em Portugal: Politicas e Circunstâncias, Lisboa: CITE.

Ferreira, Virginia (2013), "Employment and Austerity: changing welfare and gender regimes in Portugal", en Karamessini y Rubery, Women and austerity. The economic crisis and the future for gender equality, London: Routledge.

Ferreira, Virginia y Rosa Monteiro (2013), Trabalho, Igualdade e Diálogo Social: Estratégias e desafíos de um percurso, Lisboa: CITE. 
Convergencia Revista de Ciencias Sociales, núm. 72, 2016, Universidad Autónoma del Estado de México

Frade, Catarina y Lina Coelho (2015), "Surviving the Crisis and Austerity: the Coping Strategies of Portuguese Households”, en Indiana Journal of Global Legal Studies, núm. 22, Bloomington: Indiana University.

Gálvez-Muñoz, Lina et al. (2013), The impact of European austerity policy of Women's work in Southern Europe, Módena: DEMB Working Papers Series 18.

Gálvez-Muñoz, Lina (2013), “Una lectura feminista del austericidio”, en Revista de Economía Crítica, núm. 15, Madrid: Asociación Cultural de Economía Crítica.

García-Sainz, Cristina (2015), “Género y usos del tiempo”, en España 2015. Situación Social, Madrid: CIS.

Gil-Calvo, Enrique (2009), Crisis crónica. La construcción social de la gran recesión, Madrid: Alianza.

Giordano, Denis (2009), "La narrazione della precarietà: strumento di conoscenza e di divisione di pratiche", en Convegno Genere e precarietà, Trento.

Hakim, Catherine (2005), Modelos de familia en las sociedades modernas. Ideales y realidades, Madrid: CIS.

Harvey, David (2007), Breve historia del neo-liberalismo, Madrid: Akal.

Hatfield, Izzy (2015), Self-employment in Europe, London: IPPR.

Harmonised European Time Use Survey (2007), Hetus Project, Eurostat. Disponible en: http://ec.europa.eu/eurostat/en/web/products-manuals-and-guidelines/-/KSRA-08-014 [1 de marzo de 2016].

Howe, Louise Kappe (1977), Pink collar worker's: Inside the world of Women's work, Nueva York: Putnam Pub Group.

Ibáñez, Marta (2008), "La segregación ocupacional por sexo a examen. Características personales de los puestos y de las empresas asociadas a las ocupaciones masculinas y femeninas", en REIS, núm. 123, Madrid: CIS.

Informe de la Comisión Europea (2014), Tackling the gender pay gap in the European Union, Luxembourg: Directorate-General for Justice.

Informe sobre la desigualdad en España (2013), Madrid: Los Libros de la Catarata.

Informe sobre la desigualdad en España (2015), Madrid: Los Libros de la Catarata.

Ingellis, Anna Giulia y Ricard Calvo (2015), "Desempleo y crisis económica. Los casos de España e Italia”, en Sociología del Trabajo, núm. 84, Madrid: Siglo XXI.

Juan-Albalate, Joaquin (2015), Trabajo, Mercado de Trabajo y Relaciones Laborales, Madrid: Tecnos.

Karamessini, Maria y Jill Rubery [orgs.] (2013), Women and austerity. The economic crisis and the future for gender equality, London: Routledge.

Larrañaga, Mertxe (2014), “Tiempos de precariedad y desamparo”, en Viento Sur, núm. 134, Madrid: Miguel Romero.

Leite, Jorge (2013), "A reforma laboral em Portugal”, en Revista General del Derecho del Trabajo y de Seguridad Social, núm. 34, Madrid: Iustel.

Ley 3/2012 de 6 de julio, de medidas urgentes para la Reforma Laboral. BOE número 162, de 7 de julio de 2012. Disponible en: http://www.boe.es/diario_boe/txt. php?id=BOE-A-2012-9110 [4 de diciembre de 2015].

Ley 92/2012 Reforma Fornero. Disponible en: http://www.gazzettaufficiale.it/eli/ $\mathrm{id} / 2012 / 07 / 03 / 012 \mathrm{G} 0115 / \mathrm{sg}$ [5 de diciembre de 2015].

Ley de Bases de Reforma del Mercado de Trabajo (Jobs Act), Italia. Disponible en: http:// www.pmi.it/tag/riforma-del-lavoro [5 de diciembre de 2015]. 
Mercedes Alcañiz y Rosa Monteiro. She-austerity. Precariedad y desigualdad laboral de las mujeres en

Ley 53/2011 de reforma del Código de Trabajo. Disponible en: http://www.ilo.org/dyn/ natlex/docs/ELECTRONIC/89242/102436/F230751844/PRT89242.pdf [10 de diciembre de 2015].

Ley 23/2012, tercera modificación del Código de Trabajo. Disponible en: http://www.ilo. org/dyn/natlex/docs/ELECTRONIC/90599/104536/F-429263762/PRT90599. pdf [11 de diciembre 2015].

Ley 35/2014, de 20 de junio, Ley General de Trabajo en la Función Pública. Disponible en: www.ilo.org/dyn/natlex/docs/ELECTRONIC/98354/117005/F314523557/ PRT\%20-\%20Lei\%20n.o\%2035\%20-\%20Trabalho\%20na\%20funcao\%20publica. pdf [12 de diciembre de 2015].

Lorente, Raúl (2014), "Evolución del empleo temporal en España en las dos últimas crisis”, en Actas del XI Congreso Español de Sociología (FES), vol. 1, Madrid.

Leon, Margarita (2013), "Italy and Spain: still the case of familistic Welfare Mediterranean?", en Population Review, núm. 52, Delhi: Indian Institute for Population Studies.

Lerner, Gerda (1990), La creación del patriarcado, Barcelona: Crítica.

Martin-Criado, Enrique y Carlos Prieto [eds.] (2015), Conflictos por el tiempo. Poder, relación salarial y relaciones de género, Madrid: CIS.

Monteiro, Rosa (2010), "Genealogia da Lei da Igualdade no Trabalho e no emprego desde Finais do Estado Novo", en Ferreira, Virginia. A igualdade de Mulheres e Homens no Trabalho e no emprego em Portugal: Politicas e Circunstâncias, Lisboa: CITE.

Moreno-Mínguez, Almudena (2007), Familia y empleo de la mujer en los regímenes de bienestar del sur de Europa, Madrid: CIS.

Navarro, Vicenç (1998), Neoliberalismo y Estado del Bienestar, Barcelona: Ariel.

Otaegui, Amaia (2014), El deterioro laboral de las mujeres como efecto de la crisis, Madrid: Fundación $1^{\circ}$ de Mayo.

Orloff, Ann Shola (2009), "Gendering the Comparative Analysis of Welfare States: An Unfinished Agenda”, en Sociological Theory, núm. 27, Nueva York: Sage Publications.

Ortiz, Pilar (2014), "El trabajo a tiempo parcial. ¿Una alternativa para la mujer en tiempos de crisis?”, en Sociología del Trabajo, núm. 82, Siglo XXI: Madrid.

Pace, Federico (2014), “Quelli del part-time e il caso de Italia”, en La Republicca.it. Disponible en: http://miojob.republicca.it [24 de noviembre de 2015].

Pandolfini, Valeria (2014), "Families, Care and Work in European Mediterranean Countries: findings and Lessons from a comparative analysis of work-life balance policies", en Italian Sociological Review, vol. 4, núm. 1, Verona: Universidad de Verona.

Pavolini, Emmanuelle (2014), "Crisis y futuro del Estado del Bienestar en España, Italia y Portugal”, en Congreso Crisis, presente y futuro del Estado de bienestar, Oviedo: Universidad de Oviedo.

Piore, Michael y Charles Sabel (1990), La segunda ruptura industrial, Madrid: Alianza.

Prieto, Carlos, Ramos, Ramón y Javier Callejo [coords.] (2008), Nuevos tiempos del trabajo. Entre la flexibilidad competitiva de las empresas y las relaciones de género, Madrid: CIS.

Recio, Albert (2007), "Precariedad laboral: del neoliberalismo a la búsqueda de un modelo alternativo", en Congreso de Educación para el Desarrollo, Barcelona: Universidad Pompeu Fabra.

Rodríguez-Cabrero, Gregorio (2010), "El gasto público social”, en Economistas, núm. 28, Madrid: Colegio de Economistas.

Rodríguez-Cabrero, Gregorio (2014), "Crisis y futuro del Estado del Bienestar en España, 
Italia y Portugal", en Congreso Crisis, presente y futuro del Estado de bienestar, Oviedo: Universidad de Oviedo.

Rubery, Jill y Anthony Rafferty (2013), “Women and Recession Revisited”, en Work, employment and society. Disponible en: https://www.researchgate.net/ publication/258200399_Women_and_Recession_[27 de noviembre de 2015].

Sarraceno, Chiara (2004), "A igualdade difícil: mulheres no mercado de trabalho em Itália e a questão não resolvida da conciliação”, en Sociología. Problemas e práticas, núm. 44, Lisboa: CIES-IUL.

Scott, Joan (1995), "Las mujeres trabajadoras en el siglo XIX”, en Duby, Georges y Michelle Perrot, Historia de las mujeres IV Volumen Siglo XIX, Barcelona: Círculo de Lectores.

Scott, Jacqueline, Crompton, Rosemary y Claire Lyonette [eds.] (2010), Gender inequalities in the $21^{\text {st }}$ century. New barriers and continuing constraints, Cheltenham: Edward Elgar.

Segnana, Ma Luisa y Paola Villa (2015), "Women and austerity in Italy”, en Exaequo, núm. 32, Lisboa: APEM.

Silva, Pedro Adao (2002), "O modelo de Welfare da Europa do Sul: Reflexões sobre a utilidade do conceito”, en Sociologia. Problemas e Práticas, núm. 38, Lisboa: CIES-IUL.

Smith, Mark et al. (2013), Women, men and working conditions in Europe, Luxembourg: Publications Office of the European Union.

Standing, Guy (2013), El precariado. Una nueva clase social, Barcelona: Pasado \& Presente.

Steger, Manfred y Ravi Roy (2011), Neoliberalismo, Madrid: Alianza.

Stiglitz, Joseph E. (2010), Caida libre. El libre mercado y el hundimiento de la economía global, Madrid: Taurus.

Stiglitz, Joseph E. (2002), El malestar en la globalización, Barcelona: Círculo de Lectores.

Tobío, Constanza (2005), Madres que trabajan, Madrid: Cátedra.

Tobío, Constanza (2015), "Uneven paths: women and welfare in Italy and Spain”, en Journal of Gender Studies. Disponible en: http://dx.doi.org/10.1080/09589236.2015.109030 4 [3 de febrero de 2016].

Todaro, Rosalba y Sonia Yáñez [eds.] (2004), El trabajo se transforma. Relaciones de producción y relaciones de género, Santiago de Chile: Centro de Estudios de la Mujer.

Torns, Teresa y Pilar Carrasquer (2007), "Cultura de la precariedad: conceptualización, pautas y dimensiones. Una aproximación desde la perspectiva del género”, en Sociedad y Utopia. Revista de Ciencias Sociales, núm. 29, Madrid: Fundación Pablo VI.

Torns, Teresa (2011), “Las mujeres y el empleo en España. ¿Un futuro venturoso?”, en Retos y oportunidades para la igualdad de género, Madrid: FOREM.

Touraine, Alain (2011), Después de la crisis. Por un futuro sin marginación, Barcelona: Paidós.

Walby, Sylvia (1990), Theorising Patriarchy, Oxford: Blackwell. 


\section{Anexo}

\section{Gráfica 1}

\section{Tasa de ocupación por sexo (\%)}

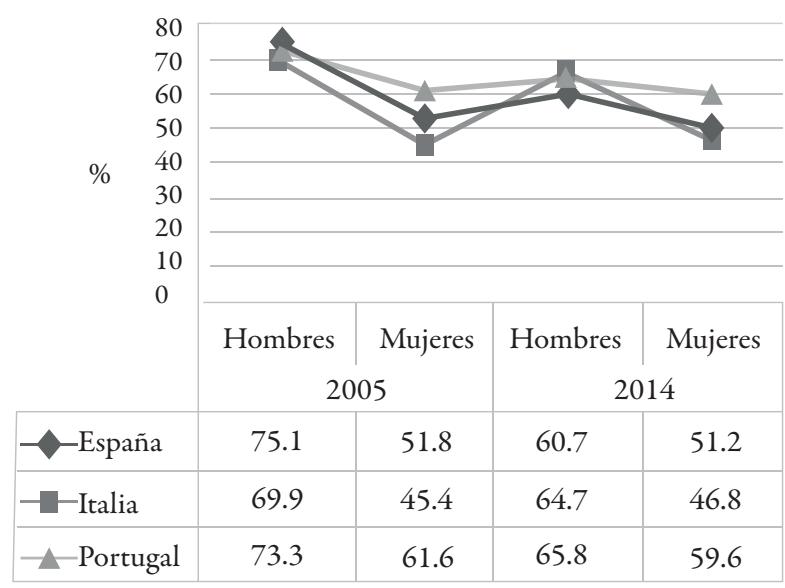

Fuente: Elaboración propia, con base en Eurostat (2015). Disponible en: www.eurostat.eu [14 de enero de 2016].

\section{Gráfica 2}

\section{Tasa de desempleo por sexo (\%)}

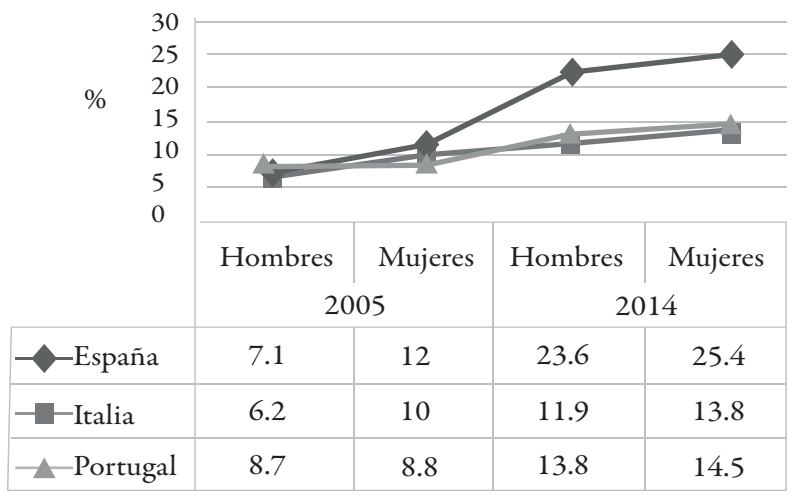

Fuente: Elaboración propia, con base en Eurostat (2015). Disponible en: www.eurostat.eu [14 de enero de 2016]. 


\section{Tabla 1}

Desempleo de larga duración por sexo sobre total del desempleo (\%)

\begin{tabular}{lcccc}
\hline & \multicolumn{2}{c}{2008} & \multicolumn{2}{c}{2015} \\
\hline & Mujeres & Hombres & Mujeres & Hombres \\
\hline España & 21,4 & 13,6 & 52,1 & 50 \\
\hline Italia & 46,6 & 45,2 & 58,7 & 59,4 \\
\hline Portugal & 45,7 & 40,9 & 55,7 & 45,6 \\
\hline
\end{tabular}

Fuente: Elaboración propia, con base en Eurostat (2015). Disponible en: www.eurostat.eu [30 de enero de 2016].

\section{Gráfica 3}

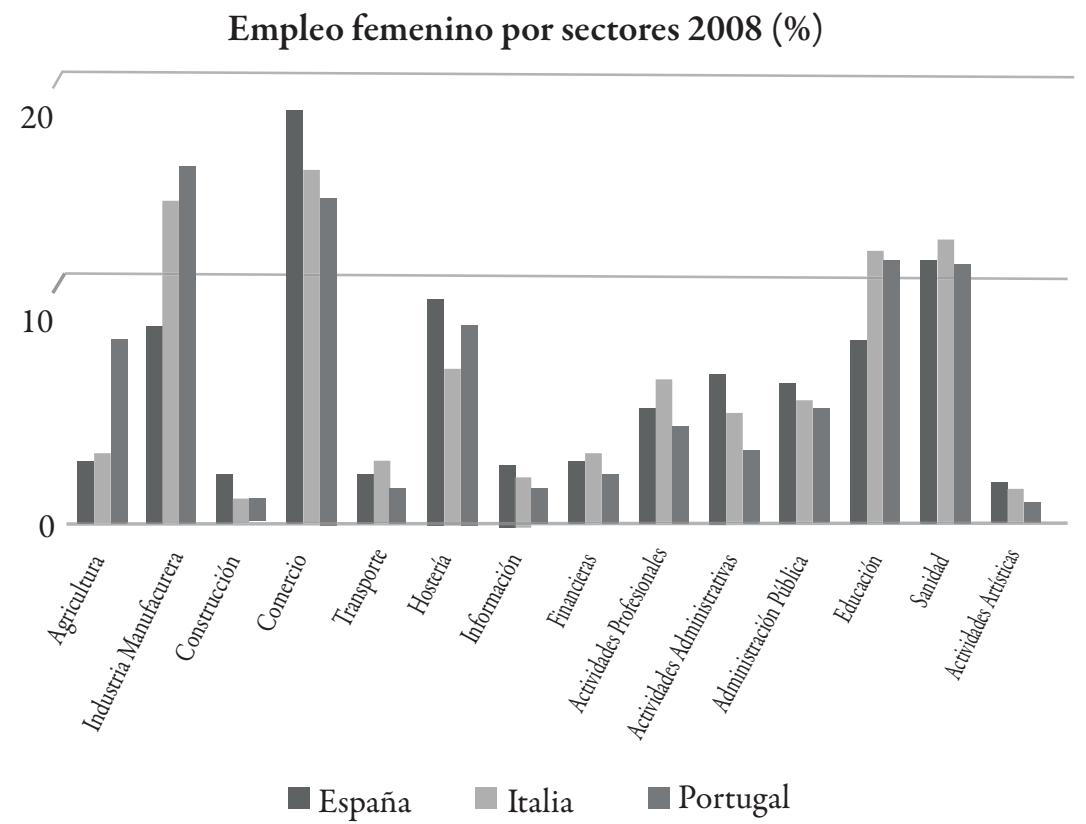

Fuente: Elaboración propia, con base en Eurostat (2015). Disponible en: www.eurostat.eu [30 de enero de 2016]. 


\section{Gráfica 4}

Empleo femenino por sectores 2015 (\%)

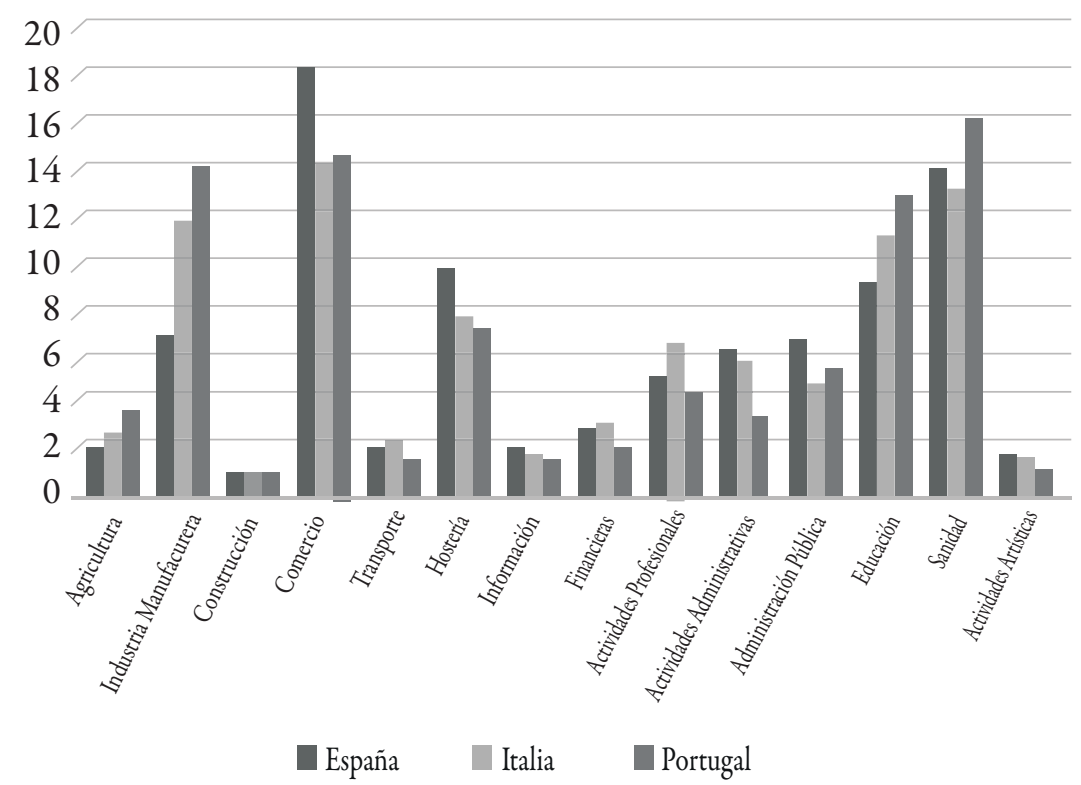

Fuente: Elaboración propia, con base en Eurostat (2015). Disponible en: www.eurostat.eu [30 de enero de 2016].

Tabla 2

Tasa de empleo según tipo de ocupación (2010)

\begin{tabular}{lcccccc}
\hline & \multicolumn{3}{c}{ Mujeres (\%) } & \multicolumn{3}{c}{ Hombres (\%) } \\
\hline & Mixtas & Masculinizadas & Feminizadas & Mixtas & Masculinizadas & Feminizadas \\
\hline España & 16 & 11 & 72 & 13 & 58 & 30 \\
\hline Italia & 42 & 11 & 59 & 26 & 45 & 14 \\
\hline Portugal & 18 & 8 & 74 & 15 & 54 & 31 \\
\hline
\end{tabular}

Fuente: Elaboración propia, con base en Brendan Burchel et al. (2014). 


\section{Tabla 3}

Tasa de empleo femenina según tipo de jornada y tipo de ocupación

\begin{tabular}{lccc}
\hline \multicolumn{4}{c}{ Mujeres empleadas con jornada a tiempo completo (\%) } \\
\hline & Mixtos & Masculinizadas & Feminizadas \\
\hline España & 18 & 13 & 69 \\
\hline Italia & 42 & 17 & 41 \\
\hline Portugal & 19 & 9 & 72 \\
\hline \multicolumn{4}{c}{ Mujeres empleadas con jornada a tiempo parcial (\%) } \\
\hline España & 9 & 5 & 86 \\
\hline Italia & 40 & 11 & 49 \\
\hline Portugal & 4 & 4 & 92 \\
\hline
\end{tabular}

Fuente: Elaboración propia, con base en Brendan Burchel et al. (2014).

\section{Gráfica 5}

\section{Indicadores de precariedad femenina 2008 (\%)}

Desempleo

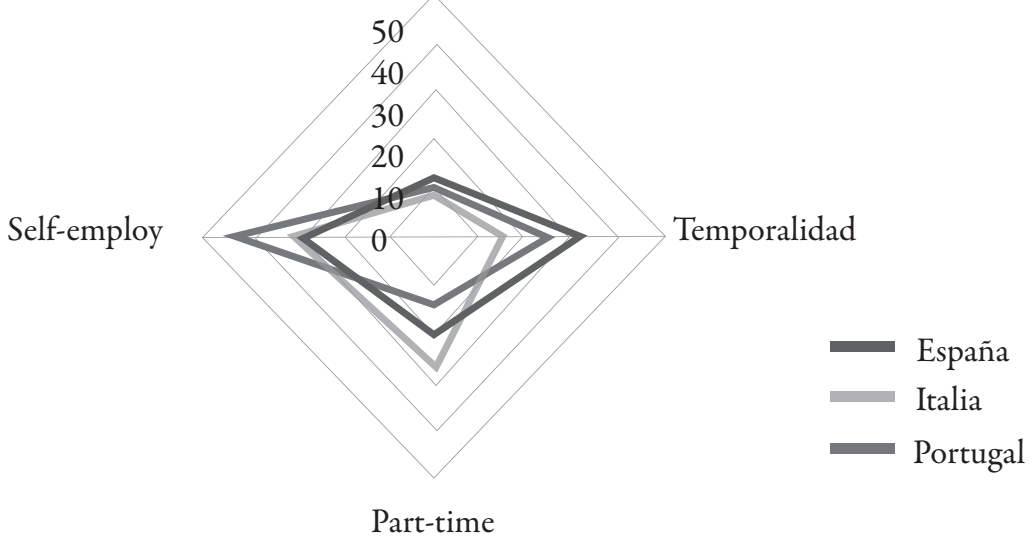

Fuente: Elaboración propia, con base en Eurostat (2015). Disponible en: www.eurostat.eu. [23 de febrero de 2016]. 


\section{Gráfica 6}

\section{Indicadores de precariedad femenina 2015}

Desempleo

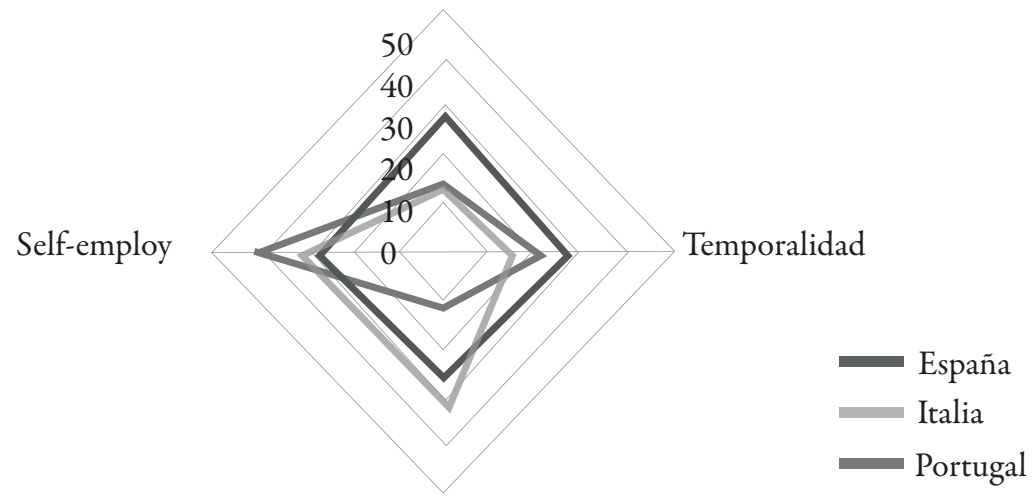

Part-time

Fuente: Elaboración propia, con base en Eurostat (2015). Disponible en: www.eurostat.eu. [23 de febrero de 2016].

\section{Tabla 5}

Usos del tiempo en Italia y en España (20 y 74 años $)^{28}$

\begin{tabular}{|c|c|c|c|c|}
\hline & \multicolumn{2}{|c|}{ Italia } & \multicolumn{2}{|c|}{ España } \\
\hline & Hombres & Mujeres & Hombres & Mujeres \\
\hline Cuidado personal & 11 h 16 & $11 \mathrm{~h} 12^{\prime}$ & 11 h 11' & $11 \mathrm{~h} \mathrm{5}$ \\
\hline Empleo & $4 \mathrm{~h} \mathrm{15}$ & $1 \mathrm{~h} \mathrm{52}$ & 4 h 21' & 2 h $6^{\prime}$ \\
\hline Estudio & $11^{\prime}$ & $14{ }^{\prime}$ & $18^{\prime}$ & $20^{\prime}$ \\
\hline Tareas de cuidado & $1 \mathrm{~h} 35^{\prime}$ & 5 h $20^{\prime}$ & $1 \mathrm{~h} 37^{\prime}$ & $4 \mathrm{~h} \mathrm{55^{ \prime }}$ \\
\hline Tiempo libre & 5 h 5' & 4 h 6 & 5 h $31^{\prime}$ & 4 h 26' \\
\hline Viaje & $1 \mathrm{~h} 35^{\prime}$ & $1 \mathrm{~h} 14$ & $1 \mathrm{~h} 10^{\prime}$ & $1 \mathrm{~h} \mathrm{5}$ \\
\hline Indeterminado & $3^{\prime}$ & $3^{\prime}$ & $2^{\prime}$ & $2^{\prime}$ \\
\hline
\end{tabular}

Fuente: Elaboración propia, con base en Harmonised European Time Use Survey (2007).

28 En España, la última Encuesta sobre Usos del tiempo se realizó en 2009-2010. Se ha elegido incluir ésta para ofrecer un marco de análisis comparativo entre los dos países. 


\section{Tabla 6}

Modificaciones en el desempeño laboral por motivos de cuidado

\begin{tabular}{cccc}
\hline & $\begin{array}{c}\text { Excedencias por } \\
\text { cuidado (3-6 meses) } \\
\text { \% Mujeres }\end{array}$ & $\begin{array}{c}\text { Abandonan empleo } \\
\text { (+ 12 meses), \% } \\
\text { Mujeres }\end{array}$ & $\begin{array}{c}\text { Reducen jornada } \\
\text { laboral \% Mujeres }\end{array}$ \\
\hline Unión Europea & 97,3 & 96,7 & 79,7 \\
\hline España & 98 & 97,7 & 89,7 \\
\hline Italia & 99,2 & 96,5 & 85,6 \\
\hline Portugal & 97,2 & - & 78,5 \\
\hline
\end{tabular}

Fuente: Elaboración propia, con base en Eurostat (2015). Disponible en: www.eurostat.eu [2 de marzo de 2016].

\section{Gráfica 7}

\section{Razones para no buscar empleo las mujeres}

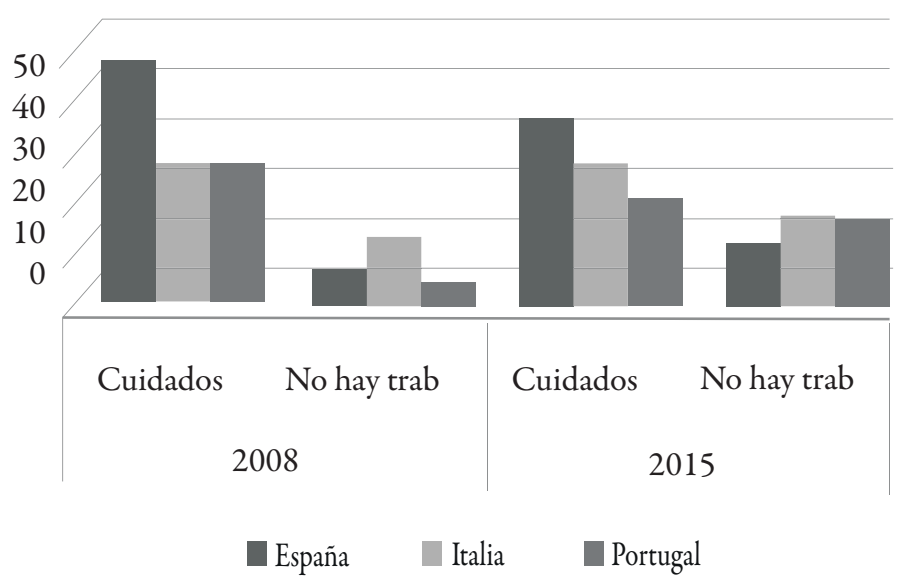

Fuente: Elaboración propia, con base en Eurostat (2015). Disponible en: www.eurostat.eu [4 de febrero de 2016]. 
Mercedes Alcañiz. Doctora en Ciencias Políticas y Sociología. Actualmente es Profesora titular de Sociología y Directora de la Unidad de Igualdad de la Universidad Jaume I de Castellón (España). Líneas de investigación: estudios de género y el cambio social. Publicaciones recientes: Cambio y continuidades de las mujeres. Un análisis sociológico Barcelona: Icaria (2011); "Género con clase: la desigual conciliación de la vida laboral y familiar”, en RES, núm. 23, Madrid: FES (2015); “Crisis, precariedad y desigualdad de género en España y en Italia”, en Obets, núm. 10, Alicante: IUDESP (2015).

Rosa Monteiro. Doctorada en Sociología por la Facultad de Economía de la Universidad de Coimbra y Centro de Estudos Sociais de la Universidad de Coimbra (Portugal). Profesora del Instituto Superior Miguel Torga. Investigadora del Centro de Estudos Sociais de la Universidad de Coimbra. Vice-presidente de la Asociación Portuguesa de Estudios sobre las Mujeres. Coordinadora de la sección Estudios y Ensayos de la revista ex aequo. Coordinadora del posgrado en Ciudadanía, Intervención y Violencia. Miembro del equipo de investigación del proyecto EEAGRANTS, Local Gender Equality. Líneas de investigación: género y políticas públicas. Publicaciones recientes: Monteiro, Rosa y Virginia Ferreira, Trabalho, Igualdade e Diálogo Social: Estratégias e desafios de um percurso, Lisboa: CITE (2013); Monteiro, Rosa, Catarina Silveiro y Fernanda Daniel, "Representações sociais do empreendorismo no masculino e no feminino", en Psicologia em Estudo, vol. 20, núm. 1, Maringá: Universidade Estadual de Maringá (2015); Ferreira, Virginia y Rosa Monteiro, "Austeridade, emprego e regime de bem-estar em Portugal: Em processo de refamilização?”, en Ex aquo, núm. 32, Lisboa: APEM (2015).

Recepción: 12 de marzo de 2016.

Aprobación: 21 de julio de 2016. 
Convergencia Revista de Ciencias Sociales, núm. 72, 2016, Universidad Autónoma del Estado de México 